\title{
Aging Impairs Protein-Synthesis-Dependent Long-Term Memory in Drosophila
}

\author{
Ayako Tonoki ${ }^{1,2}$ and Ronald L. Davis ${ }^{1}$ \\ ${ }^{1}$ Department of Neuroscience, Scripps Research Institute Florida, Jupiter, Florida 33458, and ${ }^{2}$ Graduate School of Pharmaceutical Sciences, Chiba \\ University, Chuo-ku, Chiba 260-8675, Japan
}

\begin{abstract}
Although aging is known to impair intermediate-term memory in Drosophila, its effect on protein-synthesis-dependent long-term memory (LTM) is unknown. We show here that LTM is impaired with age, not due to functional defects in synaptic output of mushroom body (MB) neurons, but due to connectivity defects of dorsal paired medial (DPM) neurons with their postsynaptic MB neurons. GFP reconstitution across synaptic partners (GRASP) experiments revealed structural connectivity defects in aged animals of DPM neurons with MB axons in the $\alpha$ lobe neuropil. As a consequence, a protein-synthesis-dependent LTM trace in the $\alpha / \beta$ MB neurons fails to form. Aging thus impairs protein-synthesis-dependent LTM along with the $\alpha / \beta$ MB neuron LTM trace by lessening the connectivity of DPM and $\alpha / \beta \mathrm{MB}$ neurons.
\end{abstract}

Key words: Drosophila; long-term memory

\section{Introduction}

Memory impairments that occur with age, one of the most common complaints of the elderly, have emerged as a very significant health threat of the 21 st century. The forms of memory impaired, the brain regions most affected, and the neurophysiological processes that become impaired with age remain issues without complete answers.

In Drosophila, olfactory classical conditioning is a robust and well studied type of learning in which olfactory cues are usually paired with electric shock such that conditioning leads to learned avoidance behavior of the odor used for conditioning (Tully and Quinn, 1985). For example, a single cycle of conditioning generates short-term memory that decays over the period of $\sim 1 \mathrm{~d}$ (Tully et al., 1994; Beck et al., 2000; Pascual and Préat, 2001). Multiple cycle conditioning with no rest between each cycle (massed conditioning) generates robust initial memory that decays over a few days, whereas introducing a rest between cycles (spaced conditioning) generates memory that persists for $4-7 \mathrm{~d}$ and is dependent on normal protein synthesis and the cAMP response element-binding protein (Creb) activity at the time of conditioning (Tully et al., 1994; Perazzona et al., 2004; Yu et al., 2006). Olfactory memories are thought to be stored in the mushroom body (MB) neurons (Dubnau et al., 2001; McGuire et al., 2001; Krashes et al., 2007), a symmetrical structure that is com-

\footnotetext{
Received March 12, 2014; revised 0ct. 27, 2014; accepted Nov. 25, 2014.

Author contributions: A.T. and R.L.D. wrote the paper.

This research was supported by the National Institute of Neurological Disorders and Stroke (Grant R37 NS19904 to R.L.D.) and by the Japan Society for the Promotion of Science (KAKENHI Grants 25115703, 26115505, and 26830003 to A.T.). We thank Barry Dickson, Scott Waddell, and the Bloomington Drosophila Stock Center for fly stocks and S. Kinoshita for technical assistance.

The authors declare no competing financial interests.

Correspondence should be addressed to Ronald L. Davis, Department of Neuroscience, Scripps Research Institute Florida, 130 Scripps Way C349, Jupiter, FL 33458. E-mail: rdavis@scripps.edu.

DOI:10.1523/JNEUROSCI.0978-14.2015

Copyright $\odot 2015$ the authors $\quad 0270-6474 / 15 / 351173-08 \$ 15.00 / 0$
}

posed of $\sim 2500$ neurons in each hemisphere and can be structurally dissected into the $\alpha / \beta, \alpha^{\prime} / \beta^{\prime}$, and $\gamma$ neuron systems (Crittenden et al., 1998; Lee et al., 1999). Functionally, the different $\mathrm{MB}$ neurons seem to participate in different aspects of memory processing, as revealed through behavioral studies, although this relationship is complex and not fully understood. Both the $\gamma$ and $\alpha^{\prime} / \beta^{\prime}$ neurons appear to have roles in early forms of memory, whereas the $\alpha / \beta \mathrm{MB}$ neurons are involved in longer forms of memory and retrieval (Yu et al., 2006; Krashes et al., 2007; Wang et al., 2008; Akalal et al., 2011; Davis, 2011; Qin et al., 2012; Cervantes-Sandoval et al., 2013). Furthermore, memory traces with different temporal features, as revealed by functional cellular imaging, have been mapped to different classes of MB neurons (Yu et al., 2006; Wang et al., 2008; Akalal et al., 2010; Davis, 2011).

Recent studies have shown that intermediate-term memory (ITM) detected at $1 \mathrm{~h}$ after 1 -cycle conditioning decreases as a function of age in Drosophila, which has an average lifespan of $\sim 40$ d after eclosion (Tamura et al., 2003; Tonoki and Davis, 2012). We also demonstrated by functional cellular imaging that aging compromises an ITM trace that normally forms in the dorsal paired medial (DPM) neurons after conditioning, but does not affect the formation of a short-term memory (STM) trace in the $\alpha^{\prime} / \beta^{\prime}$ MB neurons (Tonoki and Davis, 2012). However, how aging affects LTM has remained unexplored. We show here that aging does impair protein-synthesis-dependent LTM due to an age-dependent alteration in connectivity between DPM and $\alpha / \beta$ MB neurons.

\section{Materials and Methods}

Fly stocks. Cantonized $w^{1118}[w(C S 10)]$ or Canton-S flies of mixed sex were used as normal controls in our experiments. Flies carrying uas transgenes included uas-shits (Kitamoto, 2001) and uas-G-CaMP3.0 (Tian et al., 2009). Gal4 driver lines included c316-gal4, c739-gal4, and VT64246-gal4. All fly stocks were maintained at $25^{\circ} \mathrm{C}$ and $70 \%$ humidity under a 12:12 h light-dark cycle. For behavioral studies, $\sim 50$ flies of 
mixed sex were aliquoted into food vials and transferred to fresh food vials every 3 or $4 \mathrm{~d}$ until the age for training and testing was reached.

Behavior. Training and testing were performed under dim red light at $25^{\circ} \mathrm{C}$ and $70 \%$ relative humidity using the following procedures. Flies were exposed to $1 \mathrm{~min}$ of an odor paired with 12 pulses of electric shock at $90 \mathrm{~V}$ (CS+) followed by $1 \mathrm{~min}$ of a second odor without shock (CS-). Five spaced training cycles with a rest of $15 \mathrm{~min}$ between each cycle were performed for generating protein-synthesis-dependent LTM, whereas $5 \times$ massed training with no intertrial interval was performed for generating protein-synthesis-independent LTM. For behavioral measurements, two groups of flies were trained simultaneously using two different odors as the CS+. The one-half performance index (PI) for each odor was calculated as follows: (number of flies that chose the CSminus the number that chose the $\mathrm{CS}+$ )/(number of flies that chose the CS - plus the number of flies that chose the CS+). The overall PI was then calculated as the average of the two onehalf PIs for each odor.

Functional cellular imaging. Functional imaging experiments were performed as described previously (Yu et al., 2006). Flies carrying a uas transgene containing G-CaMP (Tian et al., 2009) along with the MB neuron driver $c 739$-gal4 were used. After $5 \times$ spaced training, flies were transferred into a new food vial. At 6, 12, 24, or $48 \mathrm{~h}$ after conditioning, one fly was aspirated from the vial and mounted in a pipette tip. A small area of cuticle on the dorsal aspect of the fly head was removed and the opening was covered with a small piece of plastic wrap. The flies were then mounted beneath the objective lens of a Leica TCS confocal microscope and imaged using a $488 \mathrm{~nm}$ excitation laser line. The emitted light was collected from $520 \pm 15 \mathrm{~nm}$. Odors were diluted in mineral oil, put on a piece of filter paper, and delivered from a micropipette in an air stream at a rate of $200 \mathrm{ml} / \mathrm{min}$. The delivery of odors was under the control of a solenoid-activated, three-way Teflon valve and a programmable controller such that fresh air could be delivered to each animal for a predetermined period with an instantaneous switch to odor-laced air without altering the overall flow rate. The calcium response to 3-octanol was assayed first by imaging with a $3 \mathrm{~s}$ odor exposure. After a $3 \mathrm{~min}$ interval, the calcium response to benzyaldehyde was assayed in an identical way. Images were acquired at 10 frames/s at a resolution of $256 \times 256$ pixels. Quantification of the responses was made from the pixels representing innervation of the dorsal tip of the $\alpha$ lobe in each image. The $F_{\mathrm{o}}$ value was calculated for each pixel within the region of interest as the fluorescence before odor application averaged over five successive frames. The $\delta F$ was calculated for each pixel as the difference between the highest intensity during the $3 \mathrm{~s}$ odor application and $F_{\mathrm{o}}$.

Immunohistochemistry and image analysis. We dissected and fixed fly brains at the indicated age and incubated them at $4^{\circ} \mathrm{C}$ overnight
A

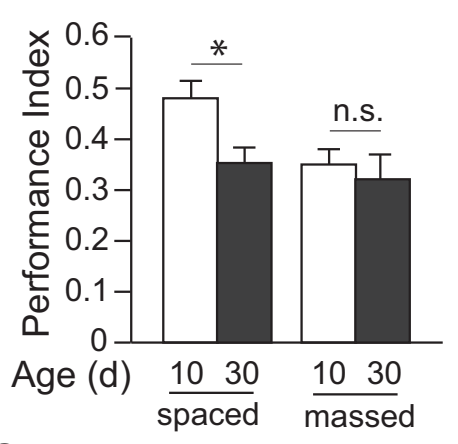

C

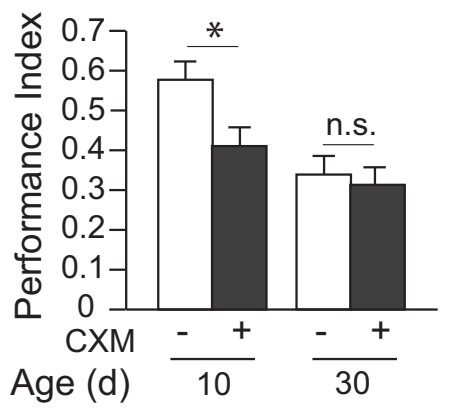

B

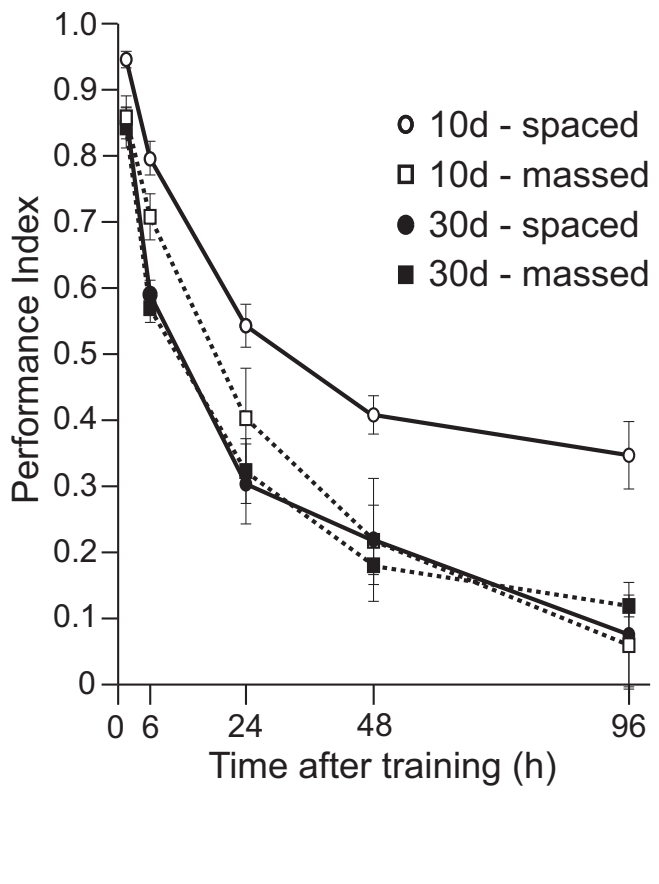

Figure 1. Aging impairs protein-synthesis-dependent LTM. $\boldsymbol{A}$, Twenty-four-hour memory after five trials of spaced training or massed training in Canton-S flies at 10 or $30 \mathrm{~d}$ of age. Thirty-day-old flies displayed significantly decreased aversive memory after spaced, but not massed, training, compared with 10-d-old flies $(n=6)$. $\boldsymbol{B}$, Memory retention curves after spaced or massed training assayed at 1.5, 6, 24, 48, and $96 \mathrm{~h}$ spaced or massed conditioning ( $n \geq 6$ for each time point). $C$, Twenty-four-hour memory after spaced training was impaired in the 10- $d$-old group fed CXM, but not in the 30-d-old group ( $n=5$ for $10 d, n=8$ for 30 d).

A

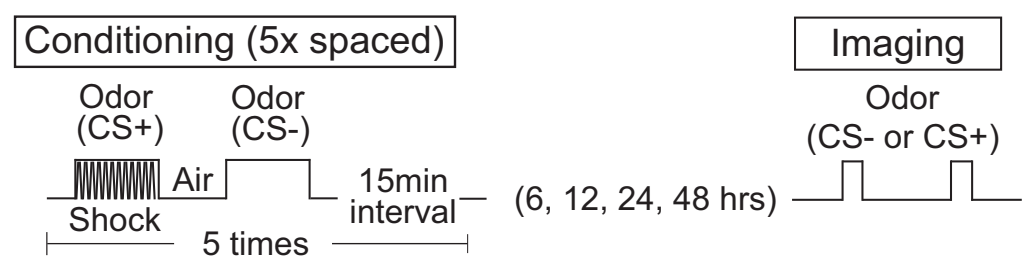

B

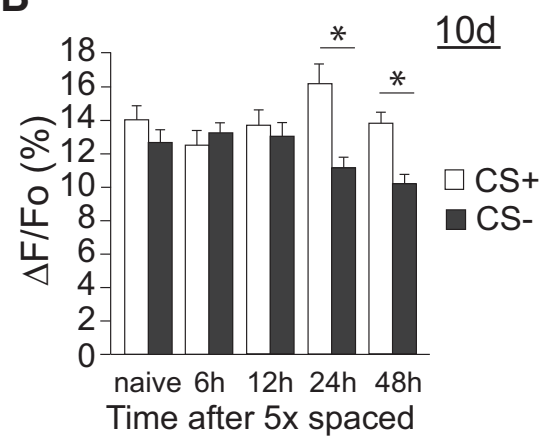

C

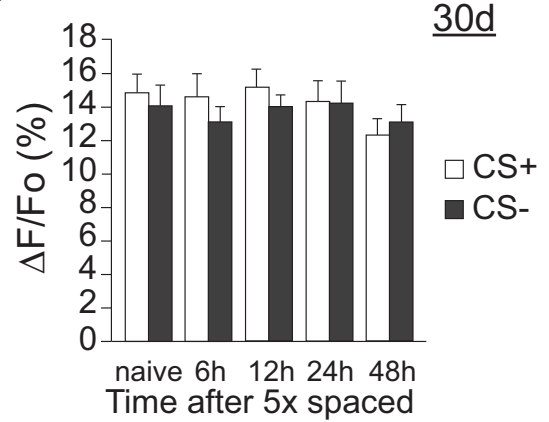

Figure 2. LTM trace disrupted by aging. $\boldsymbol{A}$, Diagram illustrating conditioning protocols used for functional cellular imaging experiments. Flies received $5 \times$ spaced training cycles with a rest of 15 min between each cycle. After conditioning, each fly was mounted in a pipette tip and prepared for functional cellular imaging. The calcium response of each fly to CS + odor was assayed first by imaging across a 3 s odor exposure. After a 3 min interval, the calcium response to the $C S$ - odor was assayed in an identical way. The functional imaging was performed at 6, 12, 24, and $48 \mathrm{~h}$ after conditioning. $\boldsymbol{B}$, Calcium responses in the $\alpha$ tip of the vertical lobes in 10-d-old flies. As a control, imaging was performed using flies without conditioning (naive). A significant increase in $\% \delta F / F_{0}$ in response to $C S+$ odor was detected at 24 and $48 \mathrm{~h}$ after conditioning ( $\left.n \geq 20\right)$. C, Calcium responses in the $\alpha$ tip of the vertical lobes in 30 - $d$-old flies. There was no significant increase in $\% \delta F / F_{0}$ in response to $C S+$ odor across time after conditioning ( $n \geq 16)$. 
A
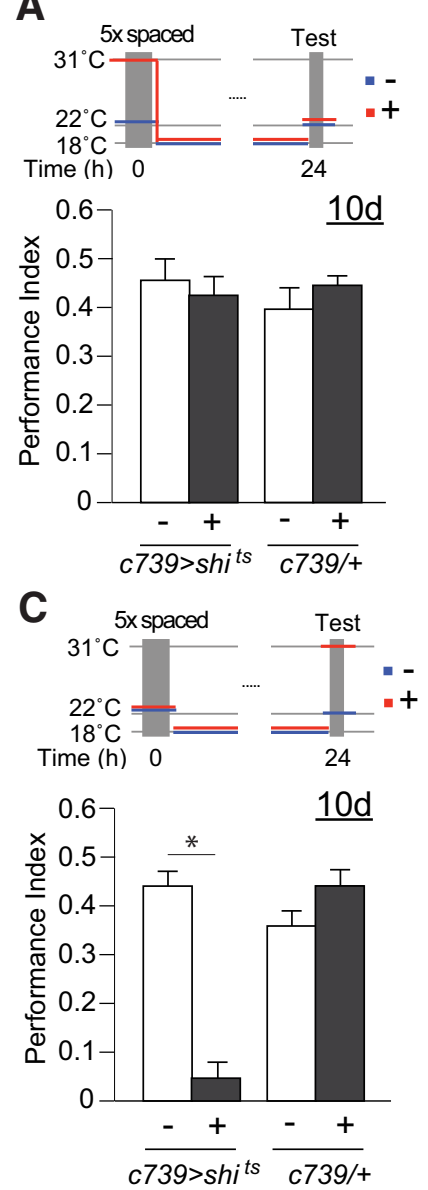

Figure 3. Synaptic transmission from MB $\alpha / \beta$ neurons and LTM. $\boldsymbol{A}$, Synaptic output from $\mathrm{MB} \alpha / \beta$ neurons is not required during conditioning of $10-\mathrm{d}$-old flies for normal LTM. Flies at $10 \mathrm{~d}$ of agewere conditioned with $5 \times$ spaced training at $22^{\circ} \mathrm{C}(-)$ or $31^{\circ} \mathrm{C}(+)$, shifted to $18^{\circ} \mathrm{C}$, and tested at $22^{\circ} \mathrm{C}(n=6) \cdot \boldsymbol{B}$, Synaptic output from $\mathrm{MB} \alpha / \beta$ neurons is not required during the early consolidation window immediately after conditioning of 10 -d-old flies for normal LTM. Flies at $10 \mathrm{~d}$ of age were conditioned with $5 \times$ spaced training at $22^{\circ} \mathrm{C}$, shifted to $22^{\circ} \mathrm{C}(-)$ or $31^{\circ} \mathrm{C}(+)$ immediately after conditioning for $3 \mathrm{~h}$, incubated at $18^{\circ} \mathrm{C}$, and tested at $22^{\circ} \mathrm{C}(n=6) . C, D$, Synaptic output from $\mathrm{MB} \alpha / \beta$ neurons is required at retrieval for normal LTM of 10 - and $30-\mathrm{d}$-old flies. Flies at 10 or $30 \mathrm{~d}$ of age were conditioned with $5 \times$ spaced training at $22^{\circ} \mathrm{C}$, shifted to $18^{\circ} \mathrm{C}$, and tested at $22^{\circ} \mathrm{C}(-)$ or $31^{\circ} \mathrm{C}(+)(n \geq 6)$.

with antibody to FasII (1:4, DSHB 1D4). Images were acquired using a Leica TCS SP5 confocal microscope. To quantify GFP signal for DPM neuron processes and GFP reconstitution across synaptic partners (GRASP), confocal $Z$-stacks of each brain were obtained at a $1 \mu \mathrm{m}$ step size using identical laser power and scanning settings between brain samples. Image stacks were collapsed to a $2 \mathrm{D}$ maximum projection image for the figures and the fluorescence within the region of interest quantified using ImageJ. Regions of interest $\left(\alpha / \alpha^{\prime}\right.$ tip, $\beta / \beta^{\prime} / \gamma$ lobes $)$ were delineated using the FasII signal and the area and mean fluorescence intensity in each region was measured using ImageJ.

\section{Results}

\section{Aging impairs protein-synthesis-dependent LTM}

We assayed memory at $24 \mathrm{~h}$ after $5 \times$ spaced training and $5 \times$ massed training in flies at 10 and $30 \mathrm{~d}$ of age. The group at $30 \mathrm{~d}$ of age exhibited impaired performance compared with the group at $10 \mathrm{~d}$ of age after spaced training, whereas there was no difference between the two groups after massed training (Fig. 1A). To compare the effects of aging more thoroughly on memory formed from spaced versus massed training, we measured memory at multiple time points in flies at the two ages. Performance indices after spaced training were significantly larger at every time point compared with memory after massed training in flies at $10 \mathrm{~d}$ of age (Fig. 1B). However, the 30 -d-old flies showed no significant difference in memory between spaced and massed training at any time point. Furthermore, the memory retention curve of $30-\mathrm{d}$ old flies after spaced conditioning was not significantly different from the memory retention curve of 10-d-old flies given massed conditioning (Fig. 1B).

There are two well described forms of consolidated memory that persist $>1$ d: protein-synthesis-dependent LTM and a form that is resistant to protein synthesis inhibitors referred to as protein-synthesis-independent LTM. Protein-synthesis-dependent LTM forms only after spaced conditioning, whereas massed conditioning generates LTM that is independent of protein synthesis (Tully et al., 1994). We tested whether the difference in $24 \mathrm{~h}$ memory induced by spaced training between 10 - and 30-d-old flies was due to an impaired ability to form protein-synthesisdependent LTM. Flies were fed on a glucose solution with or without the protein synthesis inhibitor cycloheximide (CXM) before spaced conditioning and tested $24 \mathrm{~h}$ later. We observed a significant reduction in $24 \mathrm{~h}$ behavioral performance after spaced conditioning in flies fed CXM compared with flies fed on vehicle alone in flies at $10 \mathrm{~d}$ of age. In contrast, CXM administration had no effect on performance generated by spaced conditioning in 30-d-old flies (Fig. 1C). The combined data indicate that aging impairs the formation of protein-synthesis-dependent LTM, but is without effect on protein-synthesis-independent LTM.

\section{Aging disrupts the formation of a LTM trace}

We have shown previously that a memory trace representing LTM is formed in the $\alpha / \beta \mathrm{MB}$ neurons (Yu et al., 2006). The odor-evoked calcium responses in the $\alpha / \beta \mathrm{MB}$ neurons to the learned odor increase at $9 \mathrm{~h}$ after $5 \times$ spaced conditioning in the $\alpha$, but not the $\beta$, axon branch of the $\alpha / \beta$ MB neurons. This enhancement persists through $24 \mathrm{~h}$ and requires normal protein synthesis, the activity of the transcription factor Creb, the normal function of the amnesiac gene expressed in the DPM neurons, and the normal function of 26 different LTM genes (Yu et al., 2006; Akalal et al., 2011). To determine whether aging affects the formation of the LTM trace, we measured the LTM trace that forms in the $\alpha$ axon branch of the $\alpha / \beta \mathrm{MB}$ neurons after $5 \times$ spaced conditioning of flies at 10 and $30 \mathrm{~d}$ of age. Flies expressing the calcium reporter G-CaMP in their $\alpha / \beta \mathrm{MB}$ neurons were trained and responses to both CS+ and CS- odors measured by functional cellular imaging at $6,12,24$, and $48 \mathrm{~h}$ after conditioning (Fig. 2A). Group data for the averages in peak calcium responses $\left(\% \delta F / F_{0}\right)$ are illustrated in Figure 2, $B$ and $C$, for the two age groups. In flies at $10 \mathrm{~d}$ of age, we detected a significantly increased response to CS+ odor compared with CS - odor at 24 and $48 \mathrm{~h}$ after $5 \times$ spaced conditioning (Fig. 2B). Naive flies and conditioned groups at 6 and $12 \mathrm{~h} \mathrm{ex-}$ hibited no increase in response to the CS+ odor (Fig. $2 B$ ). Similarly, the response to the CS + and CS- odors were not significantly different in 30-d-old-flies that were naive or conditioned and tested at 6 or $12 \mathrm{~h}$ (Fig. 2C). However, the 30-d-old flies differed from the 10 -d-old flies in failing to exhibit the increased response to the CS+ odor at 24 and $48 \mathrm{~h}$ (Fig. 2C). These results indicate that aging disrupts the formation or persistence of the LTM trace that forms in the $\alpha$ axon branch of the $\alpha / \beta \mathrm{MB}$ neurons. In addition, these data mesh well with the aforementioned behavioral data showing that proteinsynthesis-dependent LTM is impaired in aged flies and our prior results assigning the LTM trace to protein-synthesis-dependent LTM (Yu et al., 2006; Akalal et al., 2011). 

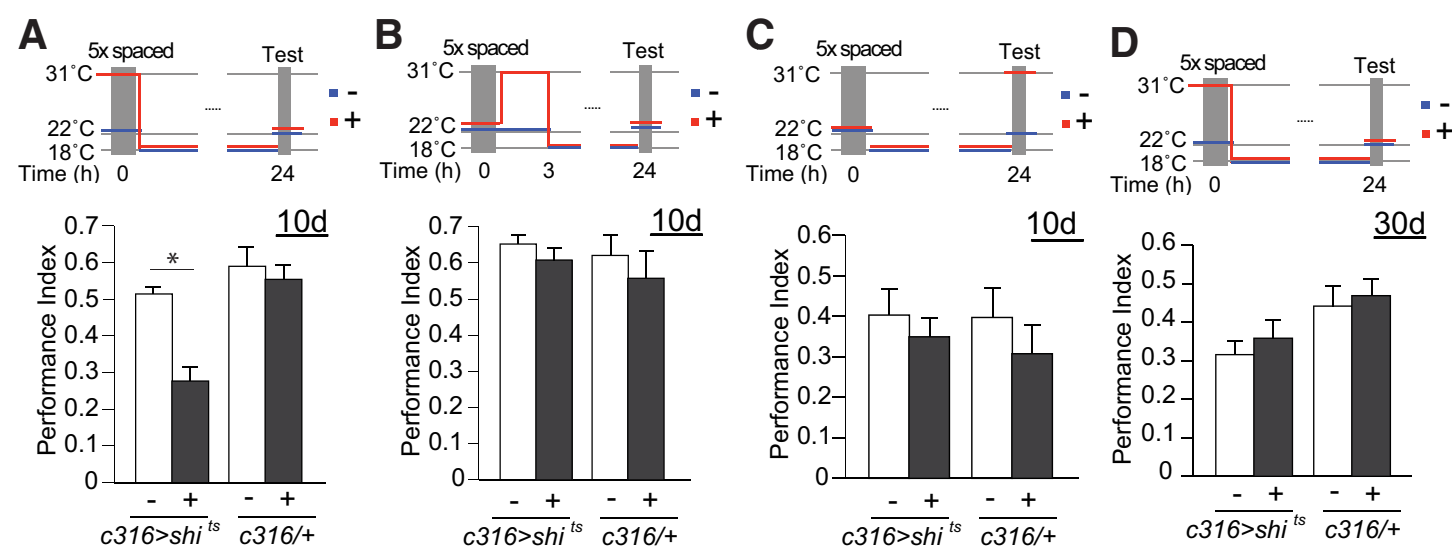

E

F

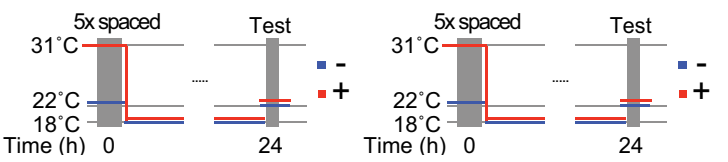

G

H
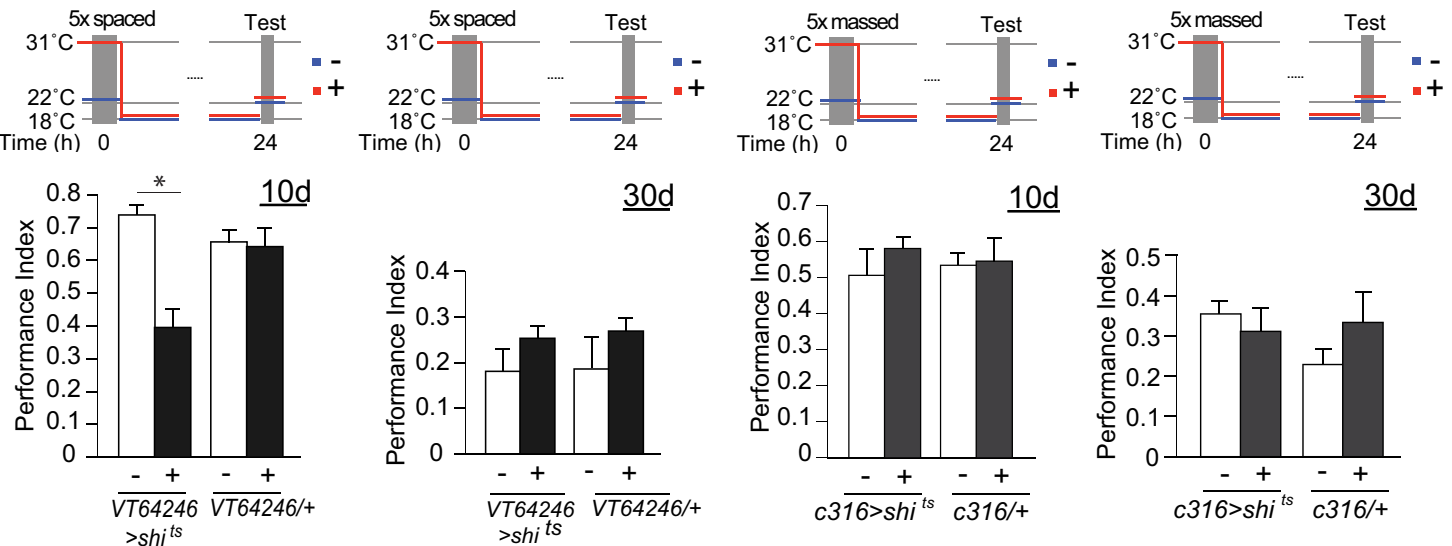

30d

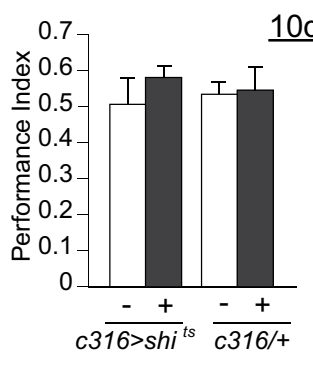

30d

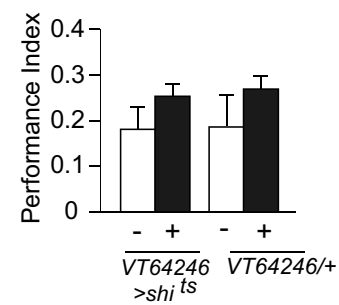

Od
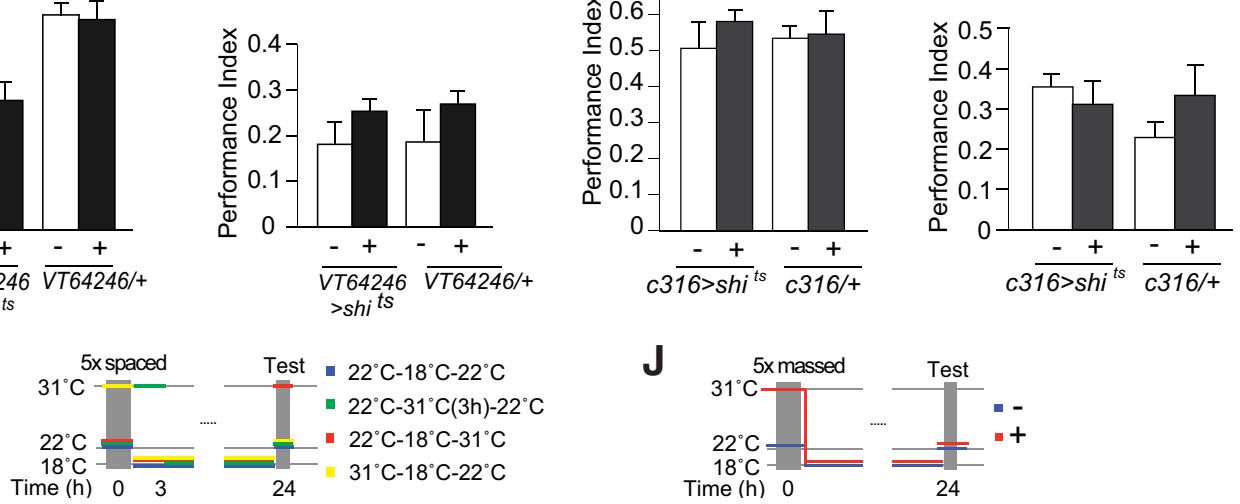

J
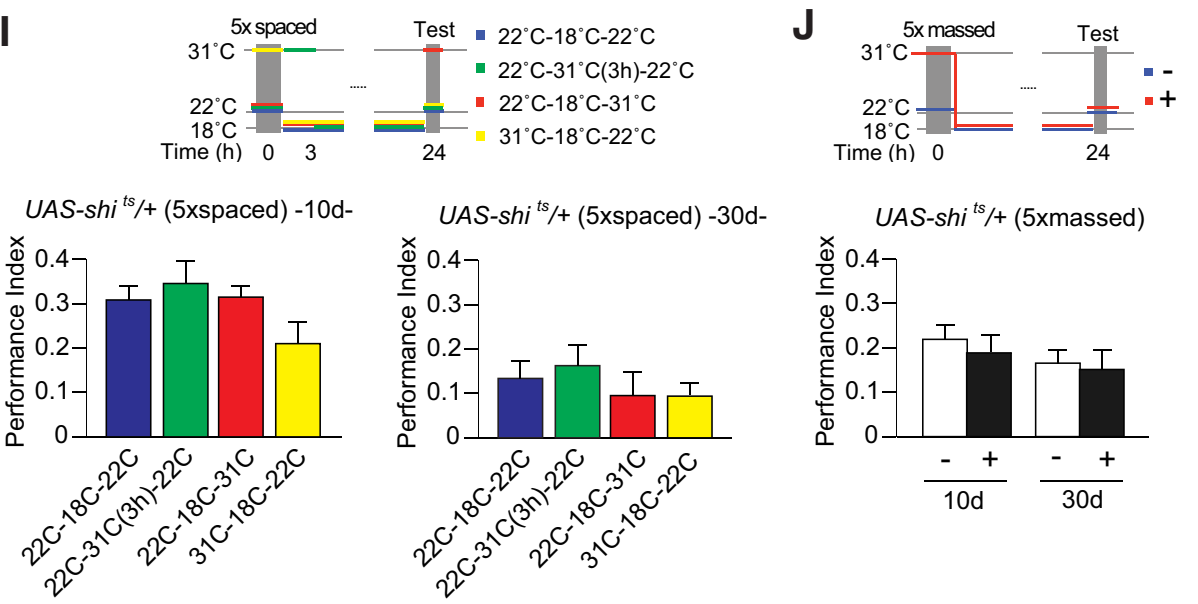

Figure 4. Synaptic transmission from DPM neurons and LTM. $A, D-F$, Synaptic output from DPM neurons is required during spaced conditioning for normal LTM of 10- but not 30-d-old flies. Flies of 10 or $30 \mathrm{~d}$ of age were conditioned with $5 \times$ spaced training at $22^{\circ} \mathrm{C}(-)$ or $31^{\circ} \mathrm{C}(+)$, shifted to $18^{\circ} \mathrm{C}$, and tested at $22^{\circ} \mathrm{C}(n \geq 6$ each). $\boldsymbol{B}$, Synaptic output from DPM neurons during the early consolidation time window is not required for LTM in flies at $10 \mathrm{~d}$ of age. Flies at $10 \mathrm{~d}$ of age were conditioned with $5 \times$ spaced training at $22^{\circ} \mathrm{C}$, shifted to $22^{\circ} \mathrm{C}(-)$ or $31^{\circ} \mathrm{C}(+)$ immediately after conditioning for $3 \mathrm{~h}$, incubated at $18^{\circ} \mathrm{C}$, and tested at $22^{\circ} \mathrm{C}(n \geq 6)$. C, Synaptic output from DPM neurons is not required at retrieval for normal LTM of 10-d-old flies. Flies at $10 \mathrm{~d}$ of age were conditioned with $5 \times$ spaced training at $22^{\circ} \mathrm{C}$, shifted to $18^{\circ} \mathrm{C}$, and tested at $22^{\circ} \mathrm{C}(-)$ or $31^{\circ} \mathrm{C}(+)(n=6) . \mathbf{G}, \boldsymbol{H}$, Synaptic output from DPM neurons is not required for LTM induced by $5 \times$ massed training during the time of conditioning in both 10 - and 30 -d-old flies. Flies were conditioned with $5 \times$ massed training at $22^{\circ} \mathrm{C}(-)$ or $31^{\circ} \mathrm{C}(+)$, shifted to $18^{\circ} \mathrm{C}$, and tested at $22^{\circ} \mathrm{C}(n \geq 6) . I, J$, No significant difference in performance at $24 \mathrm{~h}$ was observed for any temperature shift protocol using flies carrying only the uas-shi ${ }^{\text {ts }}$ element after $5 \times$ spaced conditioning $(I)$ or $5 \times$ massed conditioning $(J)$ for both 10 - and 30 -d-old flies $(n=6)$.

Aging fails to alter the synaptic transmission requirements of the $\boldsymbol{\alpha} / \boldsymbol{\beta}$ MB neurons for LTM

To further probe the effects of aging on the neurophysiological functions of $\alpha / \beta \mathrm{MB}$ neurons for LTM, we tested whether normal synaptic transmission plays a role at various times during and after spaced conditioning in 10- and 30-d-old flies. We used a temperature-sensitive shibire mutant $\left(s h i^{\text {ts }}\right)$ that expresses a dominant-negative version of dynamin and allows normal neu- rotransmission at permissive temperatures $<23^{\circ} \mathrm{C}$, but blocks neurotransmission at restrictive temperatures $>30^{\circ} \mathrm{C}$ (Kitamoto, $2001)$. Flies containing a well characterized gal4 driver specific to $\alpha / \beta \mathrm{MB}$ neurons, $c 739$-gal4, and the $u a s$-shit ${ }^{\text {ts }}$ transgene were trained with $5 \times$ spaced conditioning and tested at $24 \mathrm{~h}$ after conditioning. Blocking synaptic release across the time of conditioning (Fig. $3 A$ ) and during the $0-3 \mathrm{~h}$ time window immediately after conditioning (Fig. 3B) was without effect. In contrast, 
A
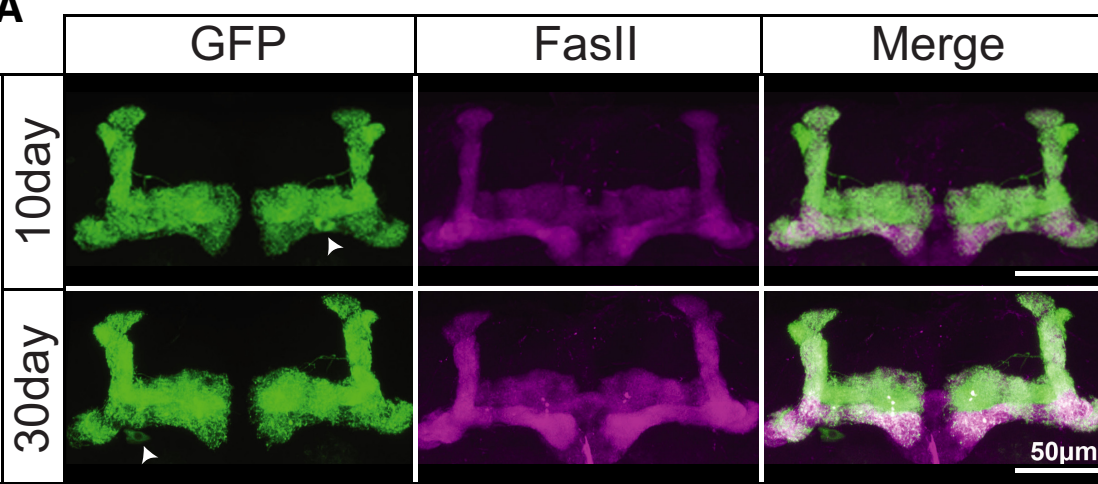

B cell body
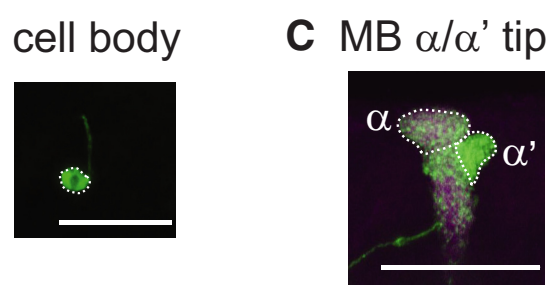

D $M B \beta / \beta^{\prime} / \gamma$ lobe

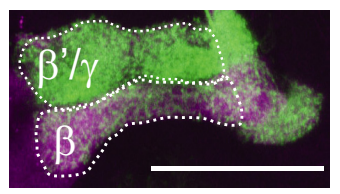

E

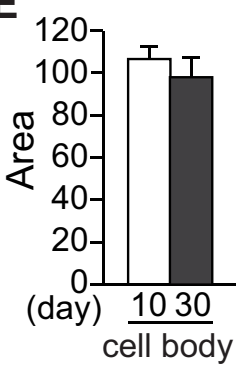

$\mathrm{H}$

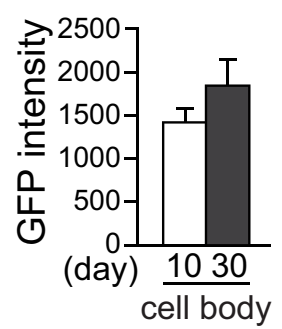

$\mathbf{F}$

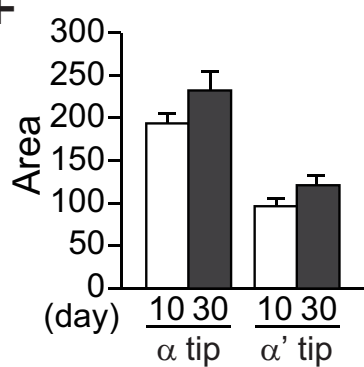

I

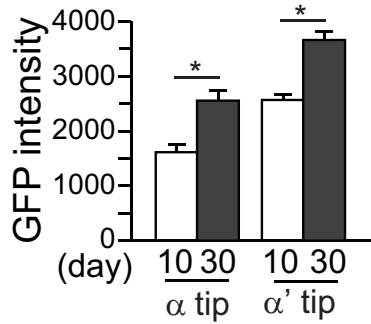

G

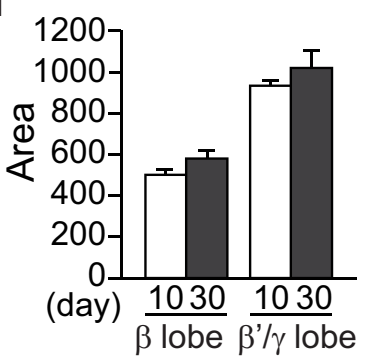

J

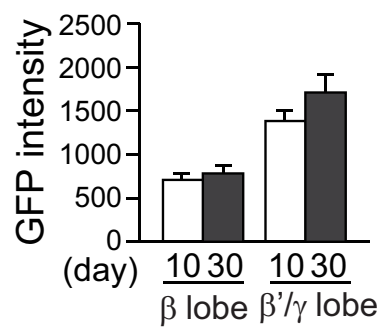

Figure 5. DPM neuron processes with aging. A, Projection images of brains of VT64246-gal4/uas-mCD8::GFP flies at the level covering the MB lobes and DPM neuron cell bodies. Left, GFP expression (green) with arrows demarking the DPM neuron cell bodies and thin processes leading to the MB lobes. Middle, Fasll immunostaining (magenta) and the right panels show merged images. $\boldsymbol{B}-\boldsymbol{D}$, Representative photos for quantification of area or GFP intensity in the cell body, $\alpha / \alpha^{\prime}$ tip of the MB, and the $\beta / \beta^{\prime} / \gamma$ lobes of the MB. $\boldsymbol{E}$, The area occupied by DPM neuron cell body was not significantly different between 10 - and 30 -d-old flies $(n=8)$. $\boldsymbol{F}$, $\boldsymbol{G}$, The area of DPM neuron processes in the $\alpha / \alpha^{\prime}$ tip and $\beta / \beta^{\prime} / \gamma$ lobes was not significantly different between 10 - and 30-d-old flies $(n=8)$. $\boldsymbol{H}$, GFP intensity from the DPM neuron cell body was not significantly different between 10 - and 30 -d-old flies ( $n=$ 8). I, GFP intensity of DPM neuron processes in the $\alpha / \alpha^{\prime}$ tip in flies at $30 \mathrm{~d}$ of age was significantly greater than that of flies at $10 \mathrm{~d}$ of age $(n=8)$. This may be due to the accumulation of GFP with age, also suggested by the trends toward increased GFP signal in 30 - $d$-old flies in other regions. J, GFP intensity of DPM neuron processes in the MB $\beta / \beta^{\prime} / \gamma$ lobe was not significantly different between 10 - and 30-d-old flies $(n=8)$. Scale bar, $50 \mu \mathrm{m}$.

protein-synthesis-dependent LTM was impaired in 10-d-old flies when neurotransmission from $\alpha / \beta \mathrm{MB}$ neurons was blocked at the time of retrieval (Fig. 3C). Synaptic blockade of $\alpha / \beta \mathrm{MB}$ neurons at the time of testing has been shown previously to severely impair performance, consistent with the model that synaptic output of these neurons mediates the retrieval of memories formed upstream of these synapses (Dubnau et al., 2001; McGuire et al., 2001; Cervantes-Sandoval et al., 2013). Control flies containing only the gal4 driver showed no change in memory performance with any of the temperature shift protocols (Fig. 3A-D). Surprisingly, flies $30 \mathrm{~d}$ of age behaved exactly as their 10-d-old counterparts, exhibiting impairment in LTM with temperature shifts at retrieval (Fig. 3C,D). Most importantly, however, these data indicate that aging does not alter the synaptic output requirements of $\alpha / \beta \mathrm{MB}$ neurons for normal LTM despite the fact that the neurophysiological requirements for the formation of the calcium-dependent LTM trace are altered.

\section{Aging occludes DPM synaptic} transmission requirement for LTM We next tested the effects of synaptic blockade of DPM neurons during $5 \times$ spaced conditioning, after training, or during the test for memory performance. LTM induced by $5 \times$ spaced conditioning was impaired when the synaptic output of DPM neurons was blocked during $5 \times$ spaced conditioning in flies at $10 \mathrm{~d}$ of age (Fig. 4A) in contrast to the absence of effect that occurred when blocking the synaptic output of $\alpha / \beta$ neurons (Fig. 3A). However, no effect was observed when a synaptic blockade in DPM neurons was imposed after training during the early consolidation time window (Fig. 4B) and at memory retrieval (Fig. $4 C$ ). To determine whether the decrement of LTM due to synaptic blockade of DPM neurons was observed with aging, 30-d-old flies were trained with $5 \times$ spaced conditioning and tested at $24 \mathrm{~h}$ after conditioning. Blocking the output of DPM neurons during $5 \times$ spaced conditioning had no effect on memory expression at $24 \mathrm{~h}$ after conditioning in flies at $30 \mathrm{~d}$ of age (Fig. 4D). We also confirmed the requirement of DPM neurons synaptic output for LTM using a more specific driver for the DPM neurons, VT64246-gal4 (Lee et al., 2011). The synaptic blockade during $5 \times$ spaced conditioning in VT64246>shits ${ }^{\text {ts }}$ flies significantly impaired memory expression at $24 \mathrm{~h}$ after conditioning at 10 but not at $30 \mathrm{~d}$ of age (Fig. $4 E, F)$. These results indicate that synaptic output of DPM neurons during $5 \times$ spaced conditioning is required for expression of LTM in young flies, but not in aged flies.

We used massed training to test the effects of synaptic blockade on protein-synthesis-independent LTM in 10 - and 30-d-old flies. The synaptic blockade of the DPM neurons during $5 \times$ massed conditioning had no effect on memory tested at $24 \mathrm{~h}$ for both 10-d-old flies (Fig. 4G) and 30-d-old flies (Fig. 4H).

We used 10- and 30-d-old flies carrying only the uas-shi ${ }^{\text {ts }}$ transgene in $5 \times$ spaced (Fig. $4 I$ ) or $5 \times$ massed conditioning protocols (Fig. $4 J$ ) to ascertain whether any phenotypes resulted from the uas$s h i^{\text {ts }}$ transgene alone. We did not observe any phenotype that could be ascribed to this transgene in isolation. 

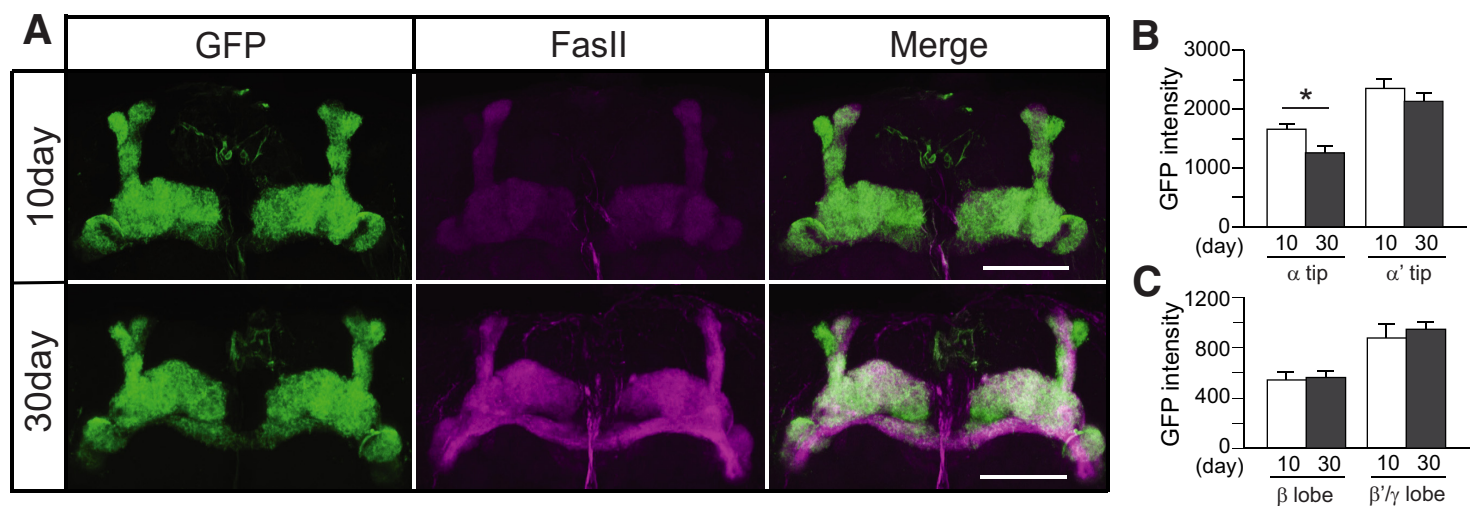

Figure 6. Age-dependent effect on contacts between DPM and MB neurons. A, Projection images of DPM neuron-MB neuron GRASP (MBGa/80/lexAop-mCD4::spGFP11;C316, 247-lexA/uas-mCD4::SpGFP1-10) fly brains. The GRASP signal reveals dense contacts between DPM and MB neurons throughout the MB neuropil innervated by DPM neuron processes. $\boldsymbol{B}$, GFP intensity of DPM neuron-MB neuron GRASP was measured in the $\alpha$ and $\alpha^{\prime}$ tip region of the MB neuropil in flies at 10 and $30 \mathrm{~d}$ of age. The GFP intensity of DPM neuron-MB neuron GRASP in flies at $30 \mathrm{~d}$ of age was significantly lower in the $\alpha$ tip, but not the $\alpha^{\prime}$ tip ( $n=8$ for $10 \mathrm{~d}$ and $n=14$ for $30 \mathrm{~d}$ ). C, GFP intensity of DPM neuron-MB neuron GRASP was measured in the $\beta / \beta^{\prime} / \gamma /$ lobe region in flies at 10 and $30 \mathrm{~d}$ of age. The GFP intensity was not significantly different in this region between the 2 age groups ( $n=8$ for $10 \mathrm{~d}$ and $n=14$ for $30 \mathrm{~d}$ ). Scale bar, $50 \mu \mathrm{m}$.

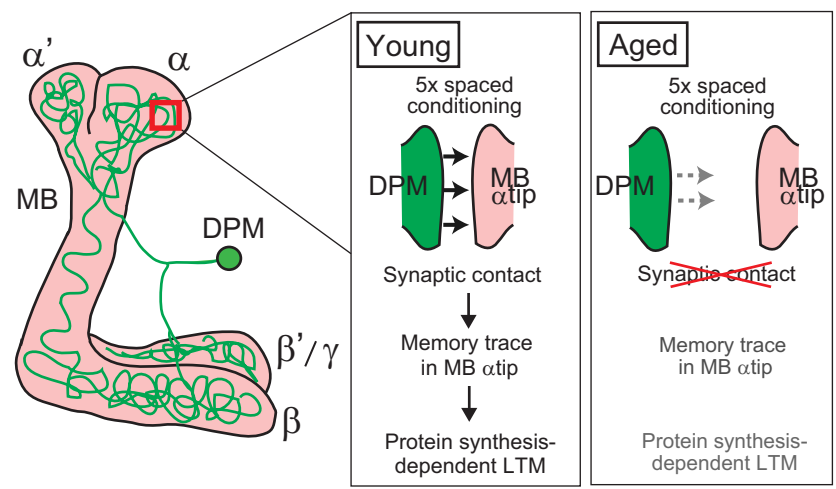

Figure 7. Model for age-dependent effect on the neural circuitry and LTM forms. DPM neuron processes ramify throughout the MB neuropil. In young flies, the formation of protein-synthesisdependent LTM requires normal synaptic transmission from DPM neurons during $5 \times$ spaced conditioning and synaptic contact of DPM neurons with axons of the $\alpha / \beta$ MB neurons residing in the tip of the $\mathrm{MB} \alpha$ lobe. In aged flies, synaptic contact between DPM and MB neurons is lost, producing the impairmentin protein-synthesis-dependent LTM and the LTM trace thatforms in the $\alpha$ lobe of theMB neuropil.

These data show that synaptic output of DPM neurons at the time of conditioning is irrelevant for the generation of proteinsynthesis-independent LTM, but this synaptic output in young flies is required for the generation of protein-synthesisdependent LTM. This requirement is eliminated in aged flies because aging disrupts protein-synthesis-dependent memory. The combined data point to the synaptic output of DPM neurons at the time of conditioning as being critical for the generation of LTM and the LTM trace in the $\alpha / \beta$ MB neurons.

\section{DPM neuron processes and aging}

The results above prompted us to consider the possibilities that aging reduces DPM neuron branching in the MB neuropil or causes improper growth of DPM neuron neurites into regions beyond the normal boundaries. Both scenarios would potentially reduce synaptic contact between DPM and $\alpha / \beta$ MB neurons, leading to the failure to generate protein-synthesis-dependent LTM. We explored these hypotheses by collecting a series of highquality, high-resolution confocal image stacks of the DPM neuron processes in flies of the two age groups. The DPM neuron processes that ramify throughout the MB lobe neuropil were visualized and analyzed in flies expressing uas-mCD8::GFP in DPM neurons with the DPM neuron-specific driver, VT64246-gal4 (Lee et al., 2011), along with immunostaining for FASII, which is a marker for $\alpha / \beta$ and $\gamma \mathrm{MB}$ axons (Crittenden et al., 1998) (Fig. 5A). We quantified the area (Fig. $5 E-G$ ) and GFP intensity (Fig. $5 H-J$ ) of DPM processes in cell body, the $\alpha / \alpha^{\prime}$ tip, and the MB $\beta / \beta^{\prime} / \gamma$ lobe (Fig. $5 B-D$ ). We observed no difference in area or GFP intensity for the cell body region between 10 - and 30-d-old flies (Fig. $5 E, H$ ), nor was there any significant difference for these parameters in the $\beta / \beta^{\prime} / \gamma$ lobes (Fig. 5G,J). Surprisingly, we observed a significant increase in GFP intensity in the $\alpha / \alpha^{\prime}$ tip in 30-d-old flies compared with their 10-d-old controls (Fig. 5I). The increase in GFP intensity may be due to increased DPM neuron branching with age within the normal spatial boundaries, but more likely represents the simple accumulation of GFP with age. The latter interpretation is supported by the trend for increased GFP expression with age in both the cell body (Fig. $5 H$ ) and the $\beta / \beta^{\prime} / \gamma$ lobe regions (Fig. $5 J$ ). Most importantly, these data offer no support for the possibility that DPM neuron-MB neuron synaptic contacts are reduced due to a reduction in the branching of the neurites of DPM neurons.

\section{Aging alters the contacts between DPM and MB neurons specifically in the $\alpha$ tip as revealed by GRASP}

We used GRASP (Feinberg et al., 2008; Gordon and Scott, 2009) to quantify the relative number of contacts between DPM and MB neurons in 10- and 30-d-old flies. GRASP is detectable when neurons expressing complementary parts of an extracellular splitGFP are close enough that functional GFP is reconstituted (Feinberg et al., 2008). We prepared flies that express lexAop-mCD4::spGFP11 in the MB neurons with 247-LexA and uas-mCD4::spGFP1-10 in the DPM neurons with c316-gal4 (Pitman et al., 2011). The GRASP signal was very dense throughout MB lobes and peduncle both in 10- and 30-d-old flies (Fig. 6A). Quantification of this signal in the $\alpha$ and $\alpha^{\prime}$ tips and the $\beta / \beta^{\prime} / \gamma$ lobe region (Fig. $6 B, C$ ) revealed that contacts between DPM and $\mathrm{MB}$ neurons are reduced in the $\alpha$ tip region in 30-d-old flies compared with flies at day 10 . Importantly, this reduction was selective, occurring only in the $\alpha$ tip region but not in the $\alpha^{\prime}$ tip or $\beta / \beta^{\prime} / \gamma$ lobe regions. 


\section{Discussion}

The data presented above offer several important findings about the neural circuitry and the forms of memory disrupted by aging. First, we show that aging impairs only one of the two mechanistically distinct forms of LTM generated by spaced, aversive classical conditioning in Drosophila. LTM that is independent of protein synthesis remains unaffected by age, whereas that form of LTM requiring protein synthesis becomes impaired. Therefore, there is mechanistic specificity in the effects of aging on LTM. Although aging, in principal, could disrupt processes like protein synthesis at the molecular level leading to a LTM deficit, our results indicate that the problem is traceable to the circuitry involved in generating protein-synthesis-dependent LTM. The normal synaptic transmission from DPM neurons onto follower neurons during spaced training that is required for generating LTM is lost with age. This is attributable to the reduction of synaptic contacts between DPM neuron processes and MB axons specifically in the tip of the $\alpha$ lobe neuropil as revealed by GRASP signals (Fig. 6). The loss of synaptic contacts between DPM and MB neurons in this region also may explain why synaptic blockade of DPM neurons during acquisition disrupts protein-synthesisdependent LTM in young but not old flies (Fig. 4). Therefore, a second major finding is that neural contacts and subsequent synaptic activity between DPM and $\alpha / \beta$ MB neurons are required for generating protein-synthesis-dependent LTM, and aging impairs this process (Fig. 7). Consistent with this model, we find that aging blocks the formation of a calcium-based, protein-synthesisdependent memory trace in the $\alpha / \beta \mathrm{MB}$ neurons (Fig. 2). Intriguingly, this memory trace forms in the $\alpha$, but not the $\beta$, lobe of the $\alpha / \beta$ $\mathrm{MB}$ neurons, essentially in the same neuropil compartment of $\mathrm{DPM} / \mathrm{MB}$ neuron contacts ( $\alpha$ lobe tip).

We found previously that ITM is impaired in flies of $30 \mathrm{~d}$ of age along with the capacity to form an ITM trace in the DPM neurons. Nevertheless, aging does not compromise the capacity to form an STM trace in the $\alpha^{\prime} / \beta^{\prime} \mathrm{MB}$ neurons (Tonoki and Davis, 2012). Therefore, aging disrupts specific temporal forms of memory, including ITM and protein synthesis LTM, but not STM and protein-synthesis-independent LTM. It is possible that the loss of connectivity of DPM neurons with the $\alpha$ tip neuropil is responsible for the loss of both ITM and protein-synthesisdependent LTM, along with their respective memory traces. We previously proposed that reciprocal activity between DPM and MB neurons underlies DPM neuron function in ITM and consolidation (Yu et al., 2005) based largely on their unique anatomy with one cell body and two processes, one innervating the vertical lobes and the other the horizontal lobes of the MBs (Waddell et al., 2000). Therefore, they receive information about learned odors from dendritic specializations in the MB lobes, process that information, and then return the processed information to the MBs. Prior studies using uas-sh ${ }^{{ }^{\text {tsl }}}$ show that synaptic transmission from DPM neurons is required after single cycle training, but is dispensable during training and retrieval (Keene et al., 2004; Yu et al., 2005). Therefore, STM appears to bypass the DPM neurons, whereas the reciprocal activity between DPM and MB neurons is required for ITM and LTM. Aging puts a kink in this neural system by impairing connectivity.

The spacing effect of training generally necessary to establish LTM has been widely reported for numerous species (Pagani et al., 2009). Recently, it was shown that the duration of the interval between training sessions required to form LTM is regulated by the corkscrew gene through waves of Ras/mitogen-activated protein kinase activity primarily in the $\mathrm{MB} \alpha / \beta$ neurons in Drosophila (Pagani et al., 2009). Notably, synaptic output from the DPM neurons is required for the formation of LTM only during spaced training, but not after spaced training or during massed training, suggesting that the spacing effect requires the synaptic output from the DPM neurons. It will be interesting to investigate a putative interaction between synaptic output from the DPM neurons during spaced training and mitogen-activated protein kinase waves in the $\mathrm{MB} \alpha / \beta$ neurons and to determine whether aging alters this interaction.

We offer a model presented in Figure 7 to explain the neural circuitry involved in protein-synthesis-dependent LTM formation and how aging impairs this form of memory. Although DPM neurons make contacts widely throughout the MB lobe neuropil with processes of many cell types, the critical interaction for LTM formation occurs in the vertical lobes of the MB through contacts onto the axons of $\alpha / \beta \mathrm{MB}$ neurons. DPM neuron synaptic activity during spaced training, which occurs due to their stimulation by $\mathrm{MB}$ neurons, promotes synaptic changes in the postsynaptic $\alpha / \beta \mathrm{MB}$ neurons and leads to the formation of memory trace in the $\alpha / \beta \mathrm{MB}$ neurons. Aging impairs protein-synthesis-dependent LTM along with a LTM trace that normally forms in the $\alpha / \beta \mathrm{MB}$ neurons by lessening the connectivity of DPM and $\alpha / \beta \mathrm{MB}$ neurons. Identifying the mechanisms by which the DPM neurons lose their connectivity with only the tips of $\alpha / \beta \mathrm{MB}$ neurons might reveal how aging impairs protein-synthesis-dependent LTM.

\section{References}

Akalal DB, Yu D, Davis RL (2010) A late-phase, long-term memory trace forms in the $\gamma$ neurons of Drosophila mushroom bodies after olfactory classical conditioning. J Neurosci 30:16699-16708. CrossRef Medline

Akalal DB, Yu D, Davis RL (2011) The long-term memory trace formed in the Drosophila $\alpha / \beta$ mushroom body neurons is abolished in long-term memory mutants. J Neurosci 31:5643-5647. CrossRef Medline

Beck CD, Schroeder B, Davis RL (2000) Learning performance of normal and mutant Drosophila after repeated conditioning trials with discrete stimuli. J Neurosci 20:2944-2953. Medline

Cervantes-Sandoval I, Martin-Peña A, Berry JA, Davis RL (2013) Systemlike consolidation of olfactory memories in Drosophila. J Neurosci 33: 9846-9854. CrossRef Medline

Crittenden JR, Skoulakis EM, Han KA, Kalderon D, Davis RL (1998) Tripartite mushroom body architecture revealed by antigenic markers. Learn Mem 5:38-51. CrossRef Medline

Davis RL (2011) Traces of Drosophila memory. Neuron 70:8-19. CrossRefMedline Dubnau J, Grady L, Kitamoto T, Tully T (2001) Disruption of neurotransmission in Drosophila mushroom body blocks retrieval but not acquisition of memory. Nature 411:476-480. CrossRef Medline

Feinberg EH, Vanhoven MK, Bendesky A, Wang G, Fetter RD, Shen K, Bargmann CI (2008) GFP Reconstitution Across Synaptic Partners (GRASP) defines cell contacts and synapses in living nervous systems. Neuron 57: 353-363. CrossRef Medline

Gordon MD, Scott K (2009) Motor control in a Drosophila taste circuit. Neuron 61:373-384. CrossRef Medline

Keene AC, Stratmann M, Keller A, Perrat PN, Vosshall LB, Waddell S (2004) Diverse odor-conditioned memories require uniquely timed dorsal paired medial neuron output. Neuron 44:521-533. CrossRef Medline

Kitamoto T (2001) Conditional modification of behavior in Drosophila by targeted expression of a temperature-sensitive shibire allele in defined neurons. J Neurobiol 47:81-92. CrossRef Medline

Krashes MJ, Keene AC, Leung B, Armstrong JD, Waddell S (2007) Sequential use of mushroom body neuron subsets during Drosophila odor memory processing. Neuron 53:103-115. CrossRef Medline

Lee PT, Lin HW, Chang YH, Fu TF, Dubnau J, Hirsh J, Lee T, Chiang AS (2011) Serotonin-mushroom body circuit modulating the formation of anesthesia-resistant memory in Drosophila. Proc Natl Acad Sci U S A 108: 13794-13799. CrossRef Medline

Lee T, Lee A, Luo L (1999) Development of the Drosophila mushroom bodies: sequential generation of three distinct types of neurons from a neuroblast. Development 126:4065-4076. Medline

McGuire SE, Le PT, Davis RL (2001) The role of Drosophila mushroom body signaling in olfactory memory. Science 293:1330-1333. CrossRef Medline 
Pagani MR, Oishi K, Gelb BD, Zhong Y (2009) The phosphatase SHP2 regulates the spacing effect for long-term memory induction. Cell 139:186198. CrossRef Medline

Pascual A, Préat T (2001) Localization of long-term memory within the Drosophila mushroom body. Science 294:1115-1117. CrossRef Medline

Perazzona B, Isabel G, Preat T, Davis RL (2004) The role of cAMP response element-binding protein in Drosophila long-term memory. J Neurosci 24:8823-8828. CrossRef Medline

Pitman JL, Huetteroth W, Burke CJ, Krashes MJ, Lai SL, Lee T, Waddell S (2011) A pair of inhibitory neurons are required to sustain labile memory in the Drosophila mushroom body. Curr Biol 21:855-861. CrossRef Medline

Qin H, Cressy M, Li W, Coravos JS, Izzi SA, Dubnau J (2012) Gamma neurons mediate dopaminergic input during aversive olfactory memory formation in Drosophila. Curr Biol 22:608-614. CrossRef Medline

Tamura T, Chiang AS, Ito N, Liu HP, Horiuchi J, Tully T, Saitoe M (2003) Aging specifically impairs amnesiac-dependent memory in Drosophila. Neuron 40:1003-1011. CrossRef Medline

Tian L, Hires SA, Mao T, Huber D, Chiappe ME, Chalasani SH, Petreanu L, Akerboom J, McKinney SA, Schreiter ER, Bargmann CI, Jayaraman V, Svoboda K, Looger LL (2009) Imaging neural activity in worms, flies and mice with improved GCaMP calcium indicators. Nat Methods 6:875881. CrossRef Medline
Tonoki A, Davis RL (2012) Aging impairs intermediate-term behavioral memory by disrupting the dorsal paired medial neuron memory trace. Proc Natl Acad Sci U S A 109:6319-6324. CrossRef Medline

Tully T, Quinn WG (1985) Classical conditioning and retention in normal and mutant Drosophila melanogaster. J Comp Physiol A 157:263-277. CrossRef Medline

Tully T, Preat T, Boynton SC, Del Vecchio M (1994) Genetic dissection of consolidated memory in Drosophila. Cell 79:35-47. CrossRef Medline

Waddell S, Armstrong JD, Kitamoto T, Kaiser K, Quinn WG (2000) The amnesiac gene product is expressed in two neurons in the Drosophila brain that are critical for memory. Cell 103:805-813. CrossRef Medline

Wang Y, Mamiya A, Chiang AS, Zhong Y (2008) Imaging of an early memory trace in the Drosophila mushroom body. J Neurosci 28:4368-4376. CrossRef Medline

Yu D, Keene AC, Srivatsan A, Waddell S, Davis RL (2005) Drosophila DPM neurons form a delayed and branch-specific memory trace after olfactory classical conditioning. Cell 123:945-957. CrossRef Medline

Yu D, Akalal DB, Davis RL (2006) Drosophila alpha/beta mushroom body neurons form a branch-specific, long-term cellular memory trace after spaced olfactory conditioning. Neuron 52:845-855. CrossRef Medline 